\title{
DESIGN OPTIMIZATION OF INDUCTION MOTORS WITH DIFFERENTIAL EVOLUTION ALGORITHMS WITH AN APPLICATION IN TEXTILE SPINNING
}

\author{
C. Thanga Raj ${ }^{1}$, Radha Thangaraj ${ }^{1}$, Millie Pant ${ }^{1}$, Pascal Bouvry ${ }^{2}$, and \\ Ajith Abraham ${ }^{3,4}$ \\ ${ }^{1}$ Indian Institute of Technology Roorkee, Roorkee, India \\ ${ }^{2}$ Faculty of Science, Technology and Communications, University of Luxembourg, \\ Luxembourg \\ ${ }^{3}$ Machine Intelligent Research Labs (MIR Labs), Scientific Network for Innovation and \\ Research Excellence, Auburn, Washington, USA \\ ${ }^{4}$ VSB-Technical University of Ostrava, Ostrava, Poruba, Czech Republic
}

This article deals with the design optimization of a squirrel-cage three-phase induction motor, selected as the driving power of spinning machines in the textile industry, using three newly developed versions of differential evolution (DE) algorithms called modified DE versions (CMDE, GMDE, and LMDE). Efficiency, which decides the operating or running cost of the motor (industry), is considered as the objective function. First, the algorithms are applied to design a general purpose motor with seven variables and nine performance-related parameters with their nominal values as constraints. To make the machine feasible, practically acceptable to serve in textile industries, and less costly to operate, certain constraints are modified in accordance with the demands of the spinning application. Comparison of the optimum designs with the industrial (existing) motor reveals that the motor designed by the proposed algorithms consumes less power input.

\section{INTRODUCTION}

Conservation of energy is an essential step toward overcoming the growing problems of the worldwide energy crisis and environmental degradation. In particular, developing countries are interested in increasing their awareness of inefficient power generation. Increasing energy efficiency in

The first author thanks Juergan Sachau, SCE, of the University of Luxembourg, for his support and advice during the preparation of this manuscript.

Address correspondence to C. Thanga Raj, Department of Water Resources Development and Management, Indian Institute of Technology Roorkee, Roorkee-247667, India. E-mail: thangfwt@ iitr.ernet.in 
industrial systems not only will help to increase the financial health of the industry, but it will also help to reduce the global warming rate, which is a main concern of policy makers across the world.

In energy-intensive industries such as textiles, steel, glass, and the like, savings of up to $20 \%$, generally, could be achieved through investment in or implementation of energy-efficient systems. In an integrated textile plant, appreciable amounts of energy could be saved or conserved by appropriately managing steam distribution, adjusting the air/fuel ratio in the boilers, installing cogeneration systems, improving the electrical power factor, reducing distribution losses, reducing harmonics effects, and so forth.

Three-phase induction motors (IMs) are the most commonly used machines in various electrical drives. About $70 \%$ of all industrial loads on a utility are represented by induction motors (Maljkovic, Cettolo, and Pavlica 2001). Generally, these motors have a high efficiency at rated speed and torque. However, the operation of these motors at partial loads (no balance between iron and copper losses) results in a considerable reduction in efficiency and in the power factor. The efficiency and power factor can be improved by adjusting the rotor flux in accordance with the load (Kioskesidis and Margaris 1996). To achieve this goal, the IM should either be redesigned optimally by modifying materials and construction with the help of numerical techniques or be fed through an inverter.

To conserve electrical energy in the industrial sector through a reduction in losses (minimum power consumption) of the IM, it is particularly interesting to deal with energy-intensive industries. For the present study, we have considered the case of textile industries because they are found to be energy intensive ( $4 \%$ energy cost in total input cost) in comparison with other industries such as chemical, food, computer manufacturing, and others (Palanichamy et al. 2001).

Over the years, many efforts have been made to solve the IM design problem by incorporating different kinds of constraints or objectives, including single and multiple objectives, through various mathematical programming and optimization techniques. Several techniques, including the classical ones (such as that of Hook and Jeeves and the Rosenbrok method, etc.) and the unconventional ones such as genetic algorithms (GA) and simulated annealing (SA), have been employed judiciously to improve the performance of an IM. A brief review of the methods used for the design optimization of IMs is given in the following section.

In the present study, we have considered the design optimization of a squirrel-cage three-phase IM, which is selected as the driving power of the spinning machine in the textile industry. The mathematical model of the problem, which is nonlinear in nature, subject to various constraints, is solved with the help of a basic differential evolution (DE) algorithm and its three modified variants, Cauchy Mutated Differential Evolution, 
Gaussian Mutated Differential Evolution, and Laplace Mutated Differential Evolution (CMDE, GMDE, and LMDE, respectively).

The organization of this article is as follows: the following section provides information about previous works on IM design. "Formulation of IM Design Problem" discusses the problem formulation with variables and constraints. The function of the textile spinning machine and its load diagram are given in "Textile Spinning Machine." The basic and the modified DE algorithms are briefly described in "Differential Evolution Algorithms." The experimental settings and the results of proposed algorithms are discussed in "Parameter Settings" and "Results and Discussion," respectively. "Conclusions" are stated in the final section of the article.

\section{PREVIOUS WORKS ON INDUCTION MOTOR DESIGN}

Optimal design of IM implies the design modifications of materials and construction to optimize the efficiency of the motor. In order to maximize efficiency and consequently minimize the electrical energy consumption of a three-phase induction motor, many optimization techniques have been used and suggested in the published literature. In this section we give a brief overview of both conventional as well as unconventional techniques used by researchers to optimize the efficiency of an induction motor.

\section{Conventional Optimization Techniques}

In addition to statistical methods (Han and Shapiro 1967) and the Monte Carlo technique (Anderson 1967) in the late 1960s, various mathematical programming techniques have been employed for optimizing the design of an IM. Appelbaum and Erlicki (1964) formulated the cost function of an IM, and they developed an algorithm that they applied to minimize it (Appelbaum and Erliki 1965).

A survey of various methods of nonlinear programming (Bharadwaj, Venkatesan, and Saxena 1979b) showed that the "sequential unconstrained minimization technique" (SUMT) developed by Fiacco and McCormik (1964a, 1964b) is quite general in nature and can be used to solve the problem of IM (Singh and Singh; Ramarathnam and Desai 1971; Murthy et al. 1994). Ramarathnam, Desai, and Subba Rao (1973) made a comparative study of various minimization techniques such as steepest descent, Davidion-Fletcher-Powell method, Powell's method, direct search method, and random search method for optimization of IM design.

The other search techniques that have been used successfully in the past for the optimal design of IM include the following: the Hook-Jeeves (HJ) method (Faiz and Sharifian 1995), the modified Hook-Jeeves method (MHJ) (Faiz and Sharifian 2001; Li and Rahman 1990), the Han Powel 
method (Fei, Fuchs, and Haung 1989), the modified Han Powel method (Schittkowski 1985), and the unconstrained Rosenbrock (Rosenbrock 1960) and constrained Rosenbrock methods (Hill algorithm; Bharadwaj 1979; Bharadwaj, Venkatesan, and Saxena 1979a).

In Li and Rahman (1990), the efficiency of a three-phase IM is optimized by MHJ, and the results are compared with the Han Powel method and the simple HJ method. Faiz and Sharifian (1995) considered efficiency, operating cost, and material cost as objective functions for a new design of motor and optimized by using the HJ method. The effects of supply voltage variation in the motor performance are analyzed, and it is concluded that higher efficiency can be obtained by increasing the voltage. The authors (Faiz and Sharifian 1995) observed that although different optimization techniques may be used, the results obtained are more or less similar.

In the pump load systems (Murthy et al. 1994), the following modifications help to consume minimum energy: (1) stator core length increase up to $130 \%$, (2) number of stator winding turns decrease by up to $10 \%$. An energy-efficient irrigation pump is designed using SUMT with interior penalty function approach in Murthy et al. (1994).

In Koechli et al. (2004), supply frequency, environment, and inrush currents are considered as constraints in addition to normal constraints for an optimum design of a hydraulic pump in aerospace applications.

A global optimization approach is introduced by Idir, Chang, and Dai (1997) based on the information of the error function at each computational step. Based on this information, the step size of each variable is automatically adjusted such that the error is reduced and thus approaches the global solution. Here, error is taken as an objective function (for efficiency maximization, calculate the percent efficiency in each step and find its error $[100 \%$ is percent efficiency]). If error is greater, a large step size is used for adjusting variables.

Torque pulsation is considered in (Singh and Singh 1993) as an additional constraint for an inverter-fed IM design. The flux and higher order harmonic currents are as low as possible in order to have least pulsation. In addition, stack length and stator and rotor current densities are decreased.

Sequential quadratic programming (SQP) for a nonlinear constrained optimization technique is applied to IM design by Singh and Sarkar (1992). Stator copper losses and core losses including harmonic losses are reduced by optimal selection of stator slot design, described in Kim, Kim, and Kwon (2005). Finite element method (FEM) is used to design the slot and, hence, core and winding losses are reduced by 2.22\%. IM efficiency is improved in Boglietti et al. (2005) by modifying the production technological process, called no tooling cost. 


\section{Unconventional Techniques}

The main disadvantage with the mathematical programming techniques is that they are highly sensitive to starting points, owing to a nonmonotonic solution. Consequently, the researchers began to consider unconventional algorithms.

It was shown in Cunkas and Akkaya (2006) that the application of GAs to IM design results in a $25 \%$ reduction of the total material cost. SA (Bhuvaneswari and Subramanian 2005), DE (Padma, Bhuvaneswari, and Subramanian 2007), and the particle swarm optimization (PSO) algorithm and its improved versions (Padma, Bhuvaneswari, and Subramanian 2007; Thanga Raj, Srivastava, and Agarwal 2008a; Wieczorek, Gol, and Michalewicz 1998) are used to design optimization of a three-phase IM, and it was shown that the performance is better than that of the conventional methods.

Hybridization of evolutionary programming (EP) and SA was applied to IM design in Padma, Bhuvaneswari, and Subramanian (2007). Here, EP was used to search the optimum point, whereas SA assisted EP to converge toward the optimum point. Evolutionary algorithm (EA)-based algorithm is applied in Weiczorek, Gol, and Michalewicz (1998) and produced good results in terms of convergence time/global convergence and the ability to handle discrete variables. Improved evolution strategy (ES; hybrid of SA and GA) is considered in Kim, Lee, and Jung (1998) for the motor design serving an electric vehicle. Shaking technique is included to avoid local minima, which appear in conventional ES.

Although DE is a robust and a popular optimization tool for solving complex optimization problems, as far as the authors' knowledge, motor design for textile mill application using DE has not been reported formerly, and comparison has not been made with the existing industrial motors. In this article an effort has been made to apply DE and its modified versions to the above-mentioned application.

\section{FORMULATION OF IM DESIGN PROBLEM}

The design of IMs implies the determination of the geometry and all data required for manufacturing in order to satisfy a vector of performance variables together with a set of constraints. A large number of design parameters are involved in the design of an induction machine. Selection of objective function, variables, and constraints are the main steps. The proper optimization requires an intelligent selection of objective function and constraints according to the drive's requirement, and further selection of variables that affect the objective function and the constraints. 
The general nonlinear programming problem is given by nonlinear objective function $f$, which is to be minimized /maximized with respect to the design variables $X=\left(x_{1}, x_{2}, \ldots, x_{n}\right)$ and the nonlinear inequality and equality constraints. This can be formulated as

\section{Minimize/Maximixe $f(X)$}

$$
\begin{gathered}
\text { Subject to: } g_{j}(X) \leq 0, j=1,2, \ldots, p \\
h_{k}(X)=0, k=1,2, \ldots, q \\
x_{i \min } \leq x_{i} \leq x_{i \max }(i=1, \ldots \ldots, n),
\end{gathered}
$$

where $p$ and $q$ are the number of inequality and equality constraints, respectively, and $n$ is the number of variables.

For design optimization of an IM, the design variables, constraints, objective function, and design equations are given in the following subsections.

\section{Variables}

A set $X$ of seven independent variables is listed below:

1. ampere conductors $/ \mathrm{m}, x_{1}$

2. ratio of stack length to pole pitch, $x_{2}$

3. stator slot depth to width ratio, $x_{3}$

4. stator core depth $(\mathrm{mm}), x_{4}$

5. average air gap flux densities $\left(\mathrm{wb} / \mathrm{m}^{2}\right), x_{5}$

6. stator winding current densities $\left(\mathrm{A} / \mathrm{mm}^{2}\right), x_{6}$

7. rotor winding current densities $\left(\mathrm{A} / \mathrm{mm}^{2}\right), x_{7}$

\section{Constraints}

Constraints play an important role in making a motor practically feasible and acceptable. It should be noted that the constraint that gets most affected by the variation in the objective function should be considered with special care. The constraints imposed into the design of an IM for general applications are as follows:

1. maximum stator tooth flux density, $\mathrm{wb} / \mathrm{m} 2 \leq 2$

2. stator temperature rise, ${ }^{\circ} \mathrm{C} \leq 70$

3. full load efficiency, $\mathrm{pu} \geq 0.8$

4. no load current, $\mathrm{pu} \leq 0.5$ 
5. starting torque, $\mathrm{pu} \geq 1.5$

6. maximum torque, $\mathrm{pu} \geq 2.2$

7. slip, pu $\leq 0.05$

8. full load power factor $\geq 0.8$

9. rotor temperature rise, ${ }^{\circ} \mathrm{C} \leq 70$

\section{Objective Function}

In order to reduce the running cost of the motor with the typical high load cycles of industrial or commercial applications, higher efficiency is more important. We have therefore considered the maximization of motor efficiency as an objective function.

\section{Design Equations}

The electromotive force (EMF) equation for a motor is given by

$$
E_{p h}=4.44 K_{w} f \phi T_{p h}
$$

The output equation for a three-phase IM is

$$
S=3 E_{p h} I_{p h} * 10^{-3} \mathrm{KVA} .
$$

Ampere conductors per meter is

$$
x_{1}=\frac{6 T_{p h} I_{p h}}{\pi D}
$$

Average air gap flux density is $x_{5}=\frac{\phi p}{\pi D L}$.

$$
\text { Stator slot depth is } d_{s s}=\sqrt{\frac{1000 S x_{3}}{2.22 K_{w} f Y^{2} S_{1} S_{f} x_{2} x_{5} x_{6}}}
$$

Weights of stator teeth, stator core, and iron are expressed (in kg) as

$$
\begin{gathered}
W_{t}=\frac{\delta_{i} S_{1} d_{s s} t_{s} L_{i}}{10^{3}}, \\
W_{c}=\frac{\delta_{i} \pi\left(O D-0.001 x_{4}\right) x_{4} L_{i}}{10^{3}},
\end{gathered}
$$




$$
\begin{gathered}
W_{r}=\delta_{i} L_{i}\left[\frac{\left(D^{2}-I D^{2}\right)}{4}-\frac{\left(S^{2} a_{s r}\right)}{10^{6}}\right] \\
\text { where } t_{s}=\frac{\pi\left(D+0.001 d_{s s}\right)}{S_{1}}-\frac{0.001 d_{s s}}{x_{3}} .
\end{gathered}
$$

Weights of stator and rotor windings are expressed as

$$
\begin{gathered}
W_{s w}=\frac{S \delta_{c}\left(x_{2}+1.15+0.12\right) 10^{-3}}{2.22 f K_{w} Y x_{2} x_{5} x_{6}}, \\
W_{r w}=\frac{S_{2} a_{b} L_{r} 10^{6}}{10^{6}}+\frac{2 \pi a_{e} D_{e}}{10^{6}} \delta_{r}, \\
\text { where } a_{b}=\frac{382.88 S}{K_{w} f S_{2} Y^{2} x_{2} x_{5} x_{7}} .
\end{gathered}
$$

\section{Efficiency}

The efficiency of an IM can be calculated as

$$
\eta=\frac{1000 P_{o}}{1000 P_{o}+P_{c u s}+P_{c u r}+P_{\text {iron }}+P_{\text {mech }}} * 100
$$

where stator copper loss $P_{c u s}=3 I_{p h}^{2} * R_{s}$,

stator resistance $R_{s}=\frac{\rho_{c} E_{p h} x_{6}}{2.22 K_{w} f I_{p h} Y x_{5}}+\left(1+\frac{1.15}{x_{2}}+\frac{0.12}{x_{2} Y}\right)$,

rotor copper loss $P_{c u r}=\frac{\rho_{r} S_{2} I_{b}^{2}}{a_{b}}\left(L_{r}+\frac{2 D_{e}}{p}\right)$,

and iron loss $P_{\text {iron }}=W_{t} * K_{1}+W_{c} * K_{2}$.

$K_{1}$ and $K_{2}$ are specific weights $\left(\mathrm{kg} / \mathrm{m}^{3}\right)$ of the teeth and the core, respectively. Mechanical loss $\left(P_{\text {mech }}\right)$, which comprises friction and windage losses, is considered as assigned parameters. For more details on the design equations, please refer to Thanga Raj (2009).

\section{Operating Cost}

On an average, a standard motor consumes electricity equivalent to 60-100 times its purchasing price during its working life. Total running cost of the motor comprises (1) energy charge and (2) fixed demand charge. 
Energy Cost Calculation. The energy cost (Ecost) of the IM per year is calculated using Equation (16):

$$
E \cos t=C_{e} * h * P_{i n},
$$

where $C_{e}$ is Energy cost (U.S. $\left.\$ / \mathrm{kWh}\right), h$ is Total operating hour/year, $P_{i n}$ is Input power of the motor $(\mathrm{KW})$. Power factor penalty is not considered in this article because almost all the industries have centralized power factor correction equipments.

Demand Cost Calculation. Demand charge cost (Dcost) consumed by the motor per year can be calculated as

$$
D \cos t=C_{d} * 12 * P_{i n}
$$

where $C_{d}$ is Demand cost per month (U.S. \$)

The total operating cost (TOC) per year of the motor is

$$
T O C=P_{i n}\left\{\left(C_{e} * h\right)+\left(C_{d} * 12\right)\right\} .
$$

\section{TEXTILE SPINNING MACHINE}

A spinning machine manufactures the cotton into yarn, which is wound on spindles (shown in Figure 1) and is used to feed a cone-winding machine. After that it can be used to make end products (clothing, etc.) with the help of a weaving machine. A three-phase squirrel-cage IM is employed as the main drive, and its shaft load is decided by the quantity

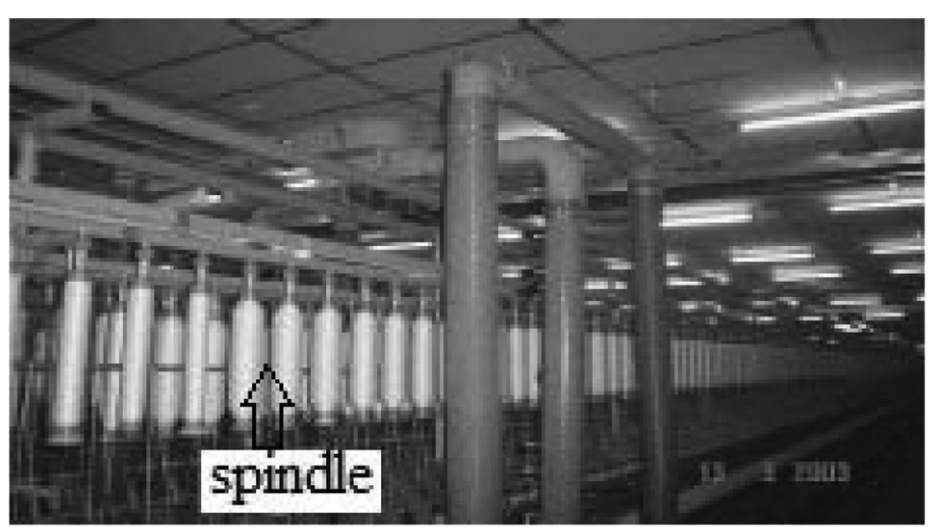

FIGURE 1 Textile spinning ring frame. 


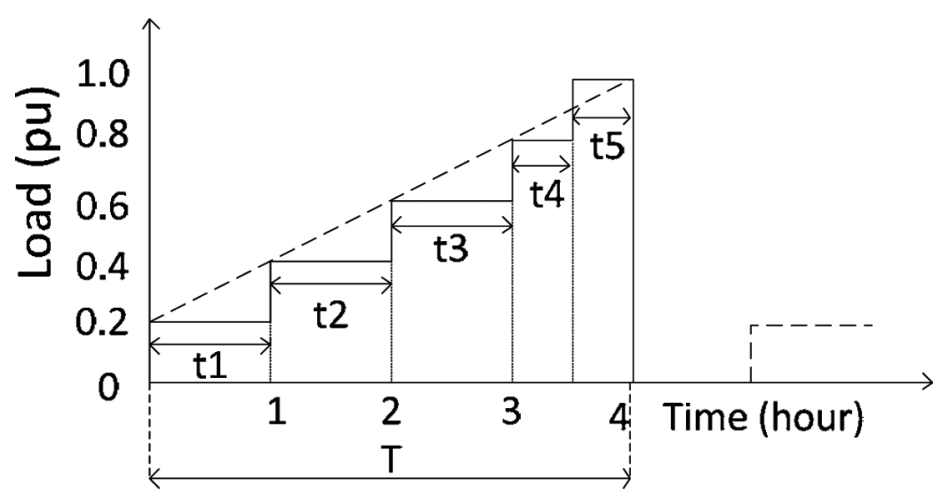

FIGURE 2 Average load diagram of a typical spinning ring frame drive motor.

of yarn in the spindles, which varies from zero (when the process starts) to full (when process completes). Therefore, the motor shaft load varies from very light to rated, shown in Figure 2. The discrete nature of the load diagram is considered for easy analysis. In Figure 2, " $\mathrm{T}$ " is the time consumption for the completion of one process.

As shown in Figure 2, the motor employed in the spinning machine undergoes partial loads during most of its operating hours. Also with this feature, there is no sudden change in the load torque and the required starting torque is less. It is noted that the motor efficiency and power factor are poor in the case of partial load. To improve them, new designs suitable for textile-mill applications are proposed by modifying the constraints. No-load current, the main source for the core losses in the motor, should be maintained as low as possible during light or partial loads. The modified constraints are

- no load current, $p u \leq 0.35$

- starting torque, $p u \geq 1.2$

- maximum torque, $p u \geq 1.75$

\section{DIFFERENTIAL EVOLUTION ALGORITHMS}

\section{Basic Differential Evolution}

Differential evolution is an EA proposed by Storn and Price (1995). DE is similar to other EAs, particularly GAs (Goldberg 1986), in the sense that it uses the same evolutionary operators such as selection, recombination, and mutation similar to that of GA. However, it is the application of these operators that make DE different from GA; whereas in GA crossover plays a significant role, it is the mutation operator that affects the working of DE 
(Karaboga and Okdem 2004). The working of basic DE may be described as follows:

Mutation. This is the first phase of the DE algorithm. In this phase a donor vector is created, corresponding to each member or target vector $X_{i, g}=\left(x_{1, i, g+1}, \ldots, x_{N, i, g+1}\right)$ in the current generation. For an $N$-dimensional search space, each target vector $X_{i, g}$, a mutant vector $V_{i, g+1}=\left(v_{1, i, g+1}, \ldots\right.$, $\left.v_{N, i, g+1}\right)$ is generated as

$$
V_{i, g+1}=X_{r_{1}, g}+F *\left(X_{r_{2}, g}-X_{r_{3}, g}\right)
$$

where $r_{1}, r_{2}, r_{3} \in\{1,2, \ldots, N P\}$ are randomly chosen integers and must be different from each other and also different from the running index $i$. Scaling factor $\mathrm{F}(>0)$ controls the amplification of the differential evolution $\left(X_{r_{2}, g}-X_{r_{3}, g}\right)$.

Crossover. Once the donor vector is generated in the mutation phase, the crossover phase of $\mathrm{DE}$ is activated. The crossover operation of DE helps in increasing the potential diversity of the DE population. The DE family of algorithms may use two types of crossover schemes: exponential (exp) and binomial (bin). During the crossover operation, the donor vector exchanges its components with the target vector $X_{i, g}$ to form a trial vector $U_{i, g+1}=\left(u_{1, i, g+1}, \ldots, u_{N, i, g+1}\right)$. In the present study we shall follow the binomial scheme. According to this scheme, the trial vectors are generated as follows:

$$
u_{j, i, g+1}=\left\{\begin{array}{lc}
v_{j, i, g+1} & \text { if } r \text { and }_{j} \leq C r \vee j=k \\
x_{j, i, g} & \text { otherwise }
\end{array}\right.
$$

where $j=1 \ldots N, k \in\{1, \ldots, N\}$ is a random parameter's index, chosen once for each $i$. A positive control parameter, $C r$, is set by the user.

Throughout the present study we shall follow $D E / \mathrm{rand} / 1 / \mathrm{bin}$ version of $\mathrm{DE}$, which is perhaps the most frequently used version and shall be referred to as the basic version.

Selection. The final phase of the DE algorithm is that of selection, which determines whether the target or the trial vector generated in the mutation and crossover phases will survive to the next generation. The population for the next generation is selected from the individual in the current population and its corresponding trial vector according to the following rule:

$$
X_{i, g+1}=\left\{\begin{array}{lc}
U_{i, g+1} & \text { if } f\left(U_{i, g+1}\right) \leq f\left(X_{i, g}\right) \\
X_{i, g} & \text { otherwise }
\end{array} .\right.
$$


Thus, each individual of the advance (trial) population is compared with its counterpart in the current population. The one with the lower objective function value (in the case of the minimization problem) will survive from the tournament selection to the population of the next generation. As a result, all the individuals of the next generation are as good as, or better than, their counterparts in the current generation. In a DE algorithm, the trial vector is not compared against all the individuals in the current generation but only against its counterpart in the current generation.

\section{Modified Differential Evolution Algorithms}

DE has emerged as one of the most popular techniques for solving engineering design problems (Omran, Engelbrecht, and Salman 2005; Das, Abraham, and Konar 2008; Thangaraj, Pant, and Deep 2010). However, it has been observed that the performance of DE is sometimes not up to the expectations. As with most of the population-based stochastic search techniques, DE also suffers from the drawbacks, such as premature convergence and stagnation of population (Lampinen and Zelinka 2000). Several attempts have been made in literature to improve its performance (Omran, Salman, and Engelbrecht 2005; Rahnamayan, Tizhoosh, and Salama 2008; Brest et al. 2006; Thangaraj, Pant, and Abraham 2010). In continuation with the efforts to improve the working of DE in terms of convergence rate as well as solution quality, in this article we propose three modified versions of DE; viz. GMDE, CMDE, and LMDE for optimization of IM design.

Here we would like to mention that a part of this work, namely the CMDE algorithm, is already published in conference proceedings (Thangaraj et al. 2010), where we used it for solving unconstrained test problems. Encouraged by its performance, in this article we developed other modified versions and applied them to optimize the design of IM described in "Formulation of IM Design Problem."

The proposed algorithms are the simple variations of basic DEs, incorporating a mutation operator based on local neighborhood search. Each algorithm starts as the basic DE algorithm, using the same mutation, crossover, and selection operators. However, once the selection process is complete, in other words, at the end of each iteration, the best individual (say, $X_{\text {best }}$ ) of the population is mutated with the help of proposed operators to explore its neighborhood with the hope of finding a better solution. The mutation process continues until there is an improvement in the fitness of the best particle.

The mutation operators employed in the present study are based on Gaussian, Cauchy, and Laplace distributions and the corresponding 
algorithms are termed GMDE, CMDE, and LMDE, respectively. The proposed mutation schemes are defined as follows:

GMDE scheme:

$$
X_{b e s t, g}^{\prime}=X_{b e s t, g}+N(0,1)^{*}\left|X_{r_{1}, g}-X_{r_{2}, g}\right|,
$$

where $\mathrm{N}(0,1)$ is the Gaussian distributed random number with mean 0 and standard deviation 1.

CMDE scheme:

$$
X_{b e s t, g}^{\prime}=X_{b e s t, g}+C^{*}\left|X_{r_{1}, g}-X_{r_{2}, g}\right|,
$$

where $\mathrm{C}$ is the Cauchy distributed random number.

LMDE scheme:

$$
X_{b e s t, g}^{\prime}=X_{b e s t, g}+\mathrm{L} *\left|X_{r_{1}, g}-X_{r_{2}, g}\right|,
$$

where $\mathrm{L}$ is the random number generated by using Laplace distribution.

The symbols $X_{r 1, g}$ and $X_{r 2, g}$ have the usual meanings as given in the previous section. The algorithmic steps of modified DE algorithms are given in Figure 3:

Step 1 Initialize DE parameters

Step 2 Randomly initialize the positions of all particles

Step 3 Evaluate the fitness function values of all particles $\left(X_{i}\right)$ in the population

Step 3 Set $g=1$

Step 4 // Mutation

Generate mutant vectors $V_{i, g+1}$ corresponding to each target vector $X_{i, g}$ via Eqn. (19)

Step 5 // Crossover

Generate trial vector $U_{i, g+1}$ for each particle using Eqn. (20)

Step $6 / /$ Selection

Update particles position using Eqn. (21)

Step 7 // Global best particle $\left(\boldsymbol{X}_{\text {best }}\right.$ ) Mutation

Generate $X_{\text {best }}^{\prime}$ using one of the mutation operators

If $\left(f\left(X_{\text {best }}^{\prime}\right)<f\left(X_{\text {best }}\right)\right.$ )

$$
X_{\text {best }}=X_{\text {best }}^{\prime}
$$

Else

$$
\text { Go to Step } 7
$$

Step 8 Set $g=g+1$

Go to Step 8

Step 9 If (Stopping criterion is reached) then go to step 10

Else go to step 4

Step 10 Print the global best particle and the corresponding fitness function value

FIGURE 3 Flow of modified DE algorithms. 


\section{PARAMETER SETTINGS}

\section{Induction Motor Settings}

Specifications for a three-phase squirrel-cage IM considered in the present study are summarized as follows:

- Capacity $=7.5 \mathrm{~kW}$

- Voltage per phase $=400$ volts

- Frequency $=50 \mathrm{~Hz}$

- Number of poles $=4$

- Number of stator slots $=36$

- Number of rotor slots $=44$

\section{Algorithmic Settings}

Control Parameters' Settings. There are three main control parameters associated with DE, which require a proper setup (fine-tuning) for the optimum performance of the algorithm. After performing a number of experiments, we chose the following parameter settings for the proposed algorithms for all the problems considered in the present study:

- Population size $=50$

- Crossover Rate $=0.5$

- Scaling Factor $=0.5$

Stopping Criteria. For all the algorithms, the search process is terminated when one of the following conditions is satisfied:

Maximum number of generations is reached (assumed 500 generations) or

$\left|f_{\max }-f_{\min }\right|<10^{-4}$ where $f$ is the value of objective function.

Number of Runs. Because DE is a stochastic technique, more than one run is required in order to ascertain the final solution. For this study, a total of 30 runs for each experimental setting were conducted, and the best solution throughout the run was recorded.

Constraint Handling. Constraints are handled according to the approach based on repair methods suggested in Pant, Thangaraj, and Singh (2009).

$P C$ Configuration. The algorithms were developed in $\mathrm{DEV} \mathrm{C}++$ and were executed on an Intel Core 2 Duo machine with 2 GB RAM. The 
random numbers were generated using inbuilt $r$ and () function with the same seed for every algorithm.

\section{RESULTS AND DISCUSSION}

In this section we discuss the numerical results, which are categorized into two sections: (1) general purpose motor and (2) motor for textile spinning applications.

\section{Result Analysis of General Purpose Motor}

The results of a fresh design of the general purpose IM obtained from different optimization algorithms are shown in Table 1. The modified DE algorithms produced better efficiency in comparison with the basic DE algorithm. One reason this was achieved is less rotor resistance (shown in

TABLE 1 Motor Design Results for General Applications

\begin{tabular}{|c|c|c|c|c|}
\hline \multirow[b]{2}{*}{ Quantity } & \multicolumn{4}{|c|}{ Optimization algorithms } \\
\hline & $\mathrm{DE}$ & CMDE & GMDE & LMDE \\
\hline Stator bore diameter $(\mathrm{m})$ & 0.158099 & 0.185668 & 0.159151 & 0.2099 \\
\hline Stator outer diameter $(\mathrm{m})$ & 0.276065 & 0.246692 & 0.243376 & 0.313901 \\
\hline Stack length $(\mathrm{m})$ & 0.116239 & 0.181724 & 0.205027 & 0.134488 \\
\hline Stator resistance $(\Omega)$ & 1.5127 & 0.866218 & 0.657637 & 0.807496 \\
\hline Rotor resistance (referred to stator, $\Omega$ ) & 1.46183 & 0.813009 & 0.821345 & 0.832499 \\
\hline Stator reactance $(\Omega)$ & 7.374 & 0.8625 & 1.2314 & 0.9504 \\
\hline Rotor reactance $(\Omega)$ & 1.9285 & 0.3741 & 0.4369 & 0.3320 \\
\hline Magnetizing reactance $(\Omega)$ & 86.3597 & 98.2565 & 84.2817 & 84.2509 \\
\hline Efficiency & 0.882905 & 0.922966 & 0.922293 & 0.914953 \\
\hline Power factor & 0.892607 & 0.91484 & 0.893444 & 0.894768 \\
\hline Starting torque to rated torque ratio & 1.73409 & 1.56141 & 1.69261 & 1.60564 \\
\hline Pull out torque to rated torque ratio & 2.95188 & 3.69442 & 3.92984 & 3.73828 \\
\hline Cost of the materials $(\$)$ & 226.535 & 229.92 & 287.304 & 311.088 \\
\hline Weight of the materials (Kg) & 43.1443 & 39.5461 & 51.4764 & 57.3763 \\
\hline Stator slot width $(\mathrm{m})$ & 0.005849 & 0.009485 & 0.007847 & 0.007825 \\
\hline Stator slot depth $(\mathrm{m})$ & 0.021907 & 0.017404 & 0.023542 & 0.023906 \\
\hline Rotor slot width (m) & 0.004785 & 0.007761 & 0.00642 & 0.006402 \\
\hline Rotor slot depth (m) & 0.006314 & 0.005935 & 0.006516 & 0.00645 \\
\hline Stator core depth $(\mathrm{m})$ & 0.037076 & 0.013108 & 0.018571 & 0.028095 \\
\hline Ampere conductor per meter & 22096.2 & 15000 & 16519.7 & 13491.1 \\
\hline Air-gap flux density (wb/m²) & 0.694357 & 0.474362 & 0.519606 & 0.557591 \\
\hline Stator winding current density $\left(\mathrm{A} / \mathrm{mm}^{2}\right)$ & 6.79675 & 4.20569 & 3.54769 & 3.77391 \\
\hline Rotor winding current density $\left(\mathrm{A} / \mathrm{mm}^{2}\right)$ & 7.01596 & 3.66919 & 3.81299 & 4.16138 \\
\hline Stator tooth flux density $\left(\mathrm{wb} / \mathrm{m}^{2}\right)$ & 1.98255 & 1.83552 & 1.7858 & 1.61982 \\
\hline Stator temperature rise $\left({ }^{\circ} \mathrm{C}\right)$ & 47.8333 & 21.4415 & 32.1066 & 36.9625 \\
\hline No-load to full-load current ratio & 0.474747 & 0.41723 & 0.486525 & 0.486783 \\
\hline
\end{tabular}


Table 1) and, hence, fewer rotor copper losses in the motors designed by modified algorithms. Because of less rotor resistance, starting torques in the proposed designs using modified algorithms are lower than the basic version, but they are good enough to start the machine. Proposed designs using modified algorithms offer less resistance in the stator windings and, hence, fewer stator copper losses. Iron losses, proportional to the weight of iron used, are lower in CMDE in comparison with the other algorithms. Because stator and rotor losses (main sources for stator temperature rise) are fewer in the designs using modified algorithms, temperature rise in the motor is lower in comparison with the DE algorithm.

The permissible limit for maximum stator tooth flux density has been taken as $2.0 \mathrm{wb} / \mathrm{m}^{2}$, and this value in optimized designs using modified algorithms is lower than that of the basic DE algorithm. Higher value of flux density is offered in DE to produce lower material cost in comparison with CMDE, GMDE, and LMDE. As a result of this, the winding current densities used in DE have comparatively much higher values. Use of such a high current density requires many fewer slot dimensions and provides more tooth width, thus reducing the saturation in the teeth portion.

In addition, with the increase of efficiency of the motor using modified algorithms, a small increase in the power factor is observed. On the other hand, there is an increase in the manufacturing cost of the machine by $1.5 \%, 26.8 \%$, and $37.3 \%$ in CMDE, GMDE, and LMDE algorithms, respectively. This is because of increase in the weights of active materials. Because a motor consumes electricity equivalent to its manufacturing cost in just three weeks of continuous use, a small increase in manufacturing cost does not produce any significant effects on process industries. Cost per weight $(\$ / \mathrm{kg})$ of iron and copper are considered 4.7 and 8.2 , respectively, as in Faiz et al. (2000).

\section{Result Analysis of Motor Design for Textile Spinning Applications}

The results of the design of the textile spinning drive motor obtained from different optimization algorithms are shown in Table 2. GMDE and CMDE produced higher full-load efficiency of the motor in comparison with DE and LMDE. However, these values are higher in the case of the general purpose motor designed by modified $\mathrm{DE}$ versions (shown in Table 1). The limitation in no-load current and the corresponding magnetizing current are the reasons for this. Higher power factor is achieved in the new designs because of less magnetizing current in comparison with the general purpose motor. Manufacturing costs of new 
TABLE 2 Motor Design Results for Textile Spinning Applications

\begin{tabular}{|c|c|c|c|c|}
\hline \multirow[b]{2}{*}{ Quantity } & \multicolumn{4}{|c|}{ Optimization algorithms } \\
\hline & $\mathrm{DE}$ & CMDE & GMDE & LMDE \\
\hline Stator bore diameter $(\mathrm{m})$ & 0.146064 & 0.189578 & 0.257464 & 0.166297 \\
\hline Stator outer diameter $(\mathrm{m})$ & 0.267057 & 0.292955 & 0.355953 & 0.25599 \\
\hline Stack length $(\mathrm{m})$ & 0.203214 & 0.155314 & 0.156974 & 0.209098 \\
\hline Stator resistance $(\Omega)$ & 1.48236 & 0.691805 & 0.863041 & 1.0011 \\
\hline Rotor resistance (referred to stator, $\Omega$ ) & 1.70082 & 1.45168 & 1.29001 & 1.76258 \\
\hline Stator reactance $(\Omega)$ & 1.9848 & 1.6968 & 0.96648 & 2.0229 \\
\hline Rotor reactance $(\Omega)$ & 0.76616 & 0.4381 & 0.3278 & 0.6279 \\
\hline Magnetizing reactance $(\Omega)$ & 111.553 & 118.333 & 129.112 & 128.764 \\
\hline Efficiency & 0.866457 & 0.903068 & 0.896156 & 0.884736 \\
\hline Power factor & 0.916431 & 0.918119 & 0.932157 & 0.924024 \\
\hline Starting torque to rated torque ratio & 1.56518 & 1.426 & 1.45149 & 1.50955 \\
\hline Pull out torque to rated torque ratio & 2.67911 & 2.88256 & 2.99502 & 2.6891 \\
\hline Cost of the materials $(\$)$ & 367.751 & 313.605 & 410.158 & 307.778 \\
\hline Weight of the materials ( $\mathrm{Kg})$ & 72.201 & 55.2116 & 75.8986 & 56.722 \\
\hline Stator slot width $(\mathrm{m})$ & 0.005666 & 0.009301 & 0.010425 & 0.007451 \\
\hline Stator slot depth (m) & 0.020224 & 0.031689 & 0.021926 & 0.024846 \\
\hline Rotor slot width (m) & 0.004636 & 0.00761 & 0.00853 & 0.006096 \\
\hline Rotor slot depth (m) & 0.006199 & 0.004559 & 0.004153 & 0.004886 \\
\hline Stator core depth $(\mathrm{m})$ & 0.040273 & 0.02 & 0.027319 & 0.02 \\
\hline Ampere conductor per meter & 21735.7 & 17690.5 & 11714.4 & 19271.7 \\
\hline Air-gap flux density $\left(w b / m^{2}\right)$ & 0.473049 & 0.451398 & 0.365649 & 0.4 \\
\hline Stator winding current density $\left(\mathrm{A} / \mathrm{mm}^{2}\right)$ & 6.90619 & 2.83678 & 3.28976 & 4.31546 \\
\hline Rotor winding current density $\left(\mathrm{A} / \mathrm{mm}^{2}\right)$ & 6.70309 & 5.86621 & 5.16657 & 6.52796 \\
\hline Stator tooth flux density $\left(\mathrm{wb} / \mathrm{m}^{2}\right)$ & 1.33986 & 1.5323 & 1.14925 & 1.25017 \\
\hline Stator temperature rise $\left({ }^{\circ} \mathrm{C}\right)$ & 51.2437 & 36.6698 & 30.7832 & 36.0389 \\
\hline No-load to full-load current ratio & 0.34971 & 0.346997 & 0.318534 & 0.319121 \\
\hline
\end{tabular}

designs are increased as a result of the increased amount of active materials used.

To see the performance of specially designed motors throughout their operations, the motor parameters are extracted from the Table 2 and are simulated with MATLAB/SIMULINK software. The results are compared with an industrial motor (equivalent circuit parameters are taken from the catalogue: $R_{s}=0.7384, R_{r}^{\prime}=0.7402, L_{s}=L_{r}=3.045 \mathrm{mH}, L_{m}=0.1241$ ) and are shown in Figures $4-6$. There are large differences, especially at light load regions as shown in Figures 4 and 5, in power consumption between industrial motors and newly designed motors using DE and its modified versions. At region $t_{5}$ (full load), DE- and LMDE-based designs consumed more power in comparison with other designs. Starting torque and pull-out torques in all designs are sufficient to drive the load. To validate the above results, stator currents (shown in Figure 6) drawn from the supply of the motor are higher in an industrial motor at all loads, and the current difference is more in light-load regions. 


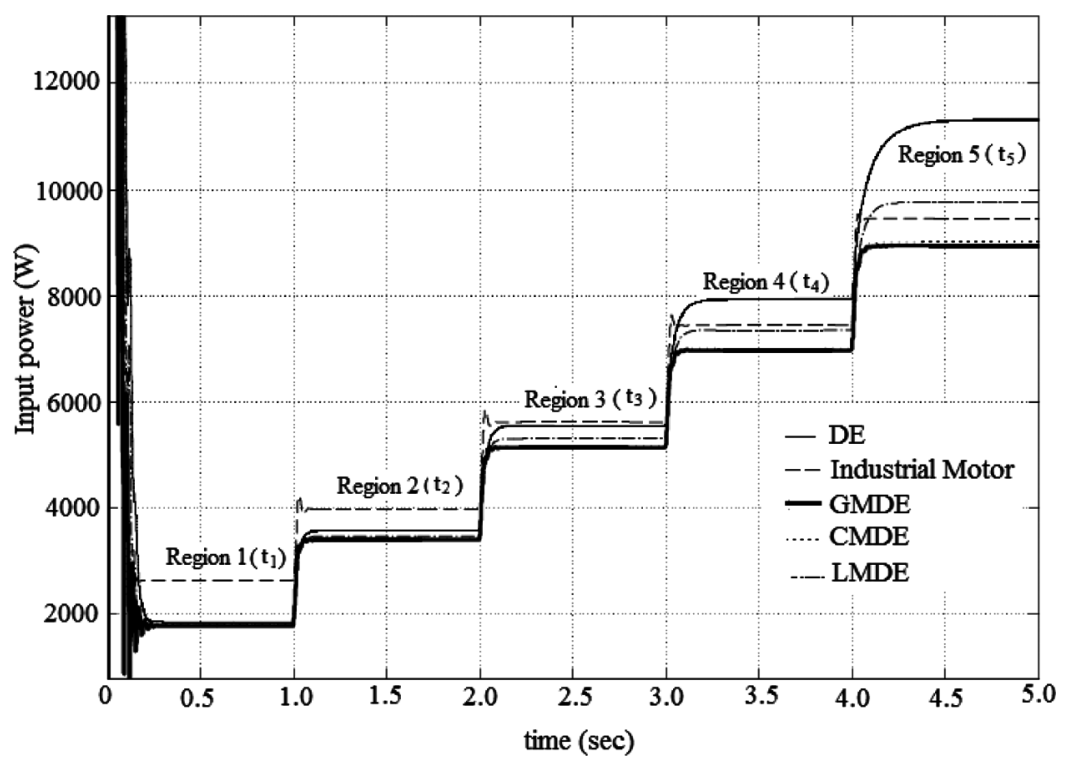

FIGURE 4 Simulation results of proposed designs for textile mill load diagram.

\section{Economic Analysis}

Economic analysis of the proposed design with respect to the given load diagram at the following electricity tariff and assuming five processes per day and 355 days of operation/year is summarized in Table 3.

- Maximum demand (KVA) charges: U.S. \$6.66/month

- Energy $(\mathrm{kWh})$ charges: U.S. $\$ 0.077 / \mathrm{kWh}$ (1 U.S. $\$=45$ Indian rupees, approximately).

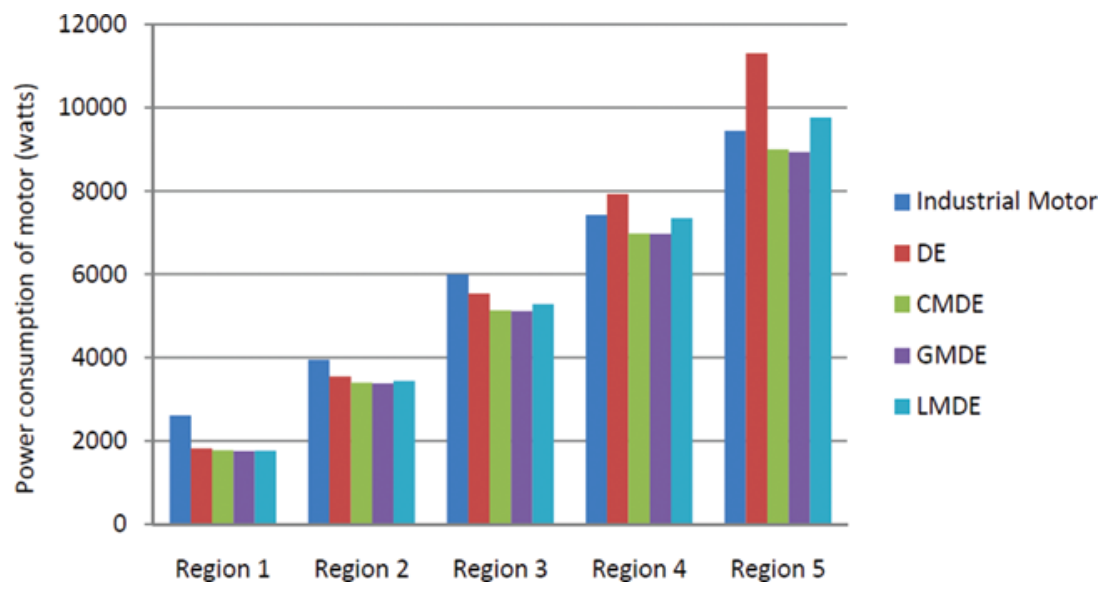

FIGURE 5 Comparison of power consumption in motors with different designs. (Color figure available online.) 


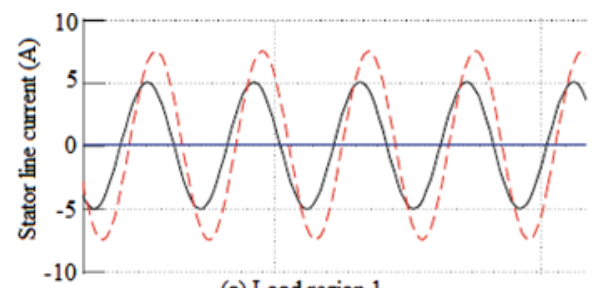

(a) Load region 1

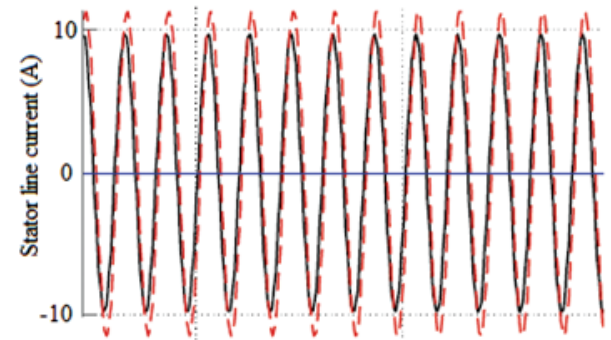

(b) Load region 2

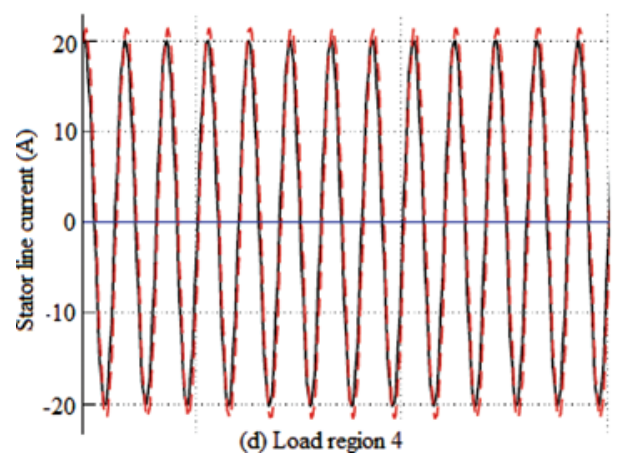

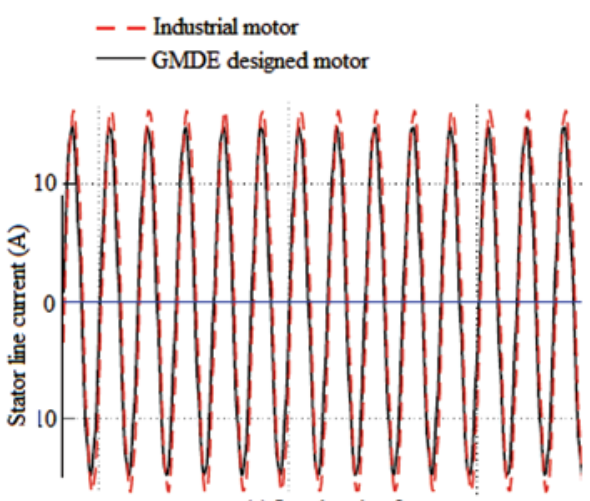

(c) Load region 3

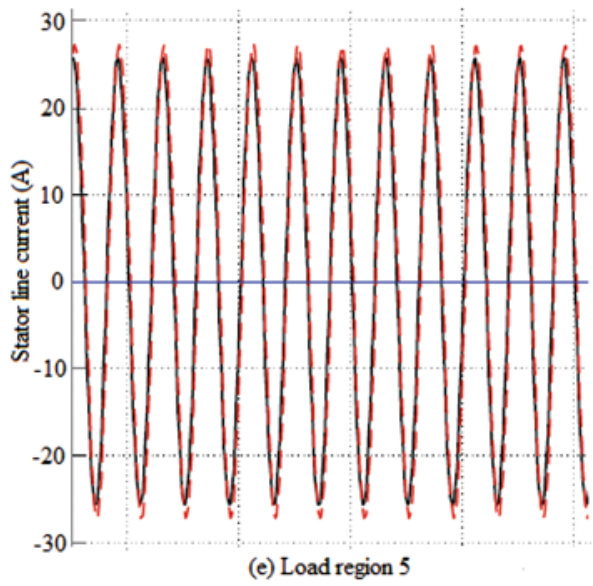

FIGURE 6 Line current of the motor at different loads. (Color figure available online.)

GMDE- and CMDE-based designs offer more savings (\$646 and \$622, respectively) in terms of operating cost in comparison with an industrial motor. There is no savings observed on the DE-based design because of excess losses in the motor, as mentioned earlier.

TABLE 3 Economic Analysis of Proposed Designs

\begin{tabular}{|c|c|c|c|c|c|c|c|c|c|}
\hline \multirow[b]{2}{*}{ Algorithms } & \multicolumn{5}{|c|}{$\begin{array}{l}\text { Less power consumption (kW) of proposed } \\
\text { motors in comparison with industrial motor }\end{array}$} & \multirow{2}{*}{$\begin{array}{c}\text { Total } \\
\text { kWh } \\
\text { saving }\end{array}$} & \multirow{2}{*}{$\begin{array}{c}\text { Ecost } \\
(\$ / \text { year })\end{array}$} & \multirow{2}{*}{$\begin{array}{c}\text { Dcost } \\
(\$ / \text { year })\end{array}$} & \multirow{2}{*}{$\begin{array}{c}\text { Total } \\
\text { saving } \\
(\$ / \text { year })\end{array}$} \\
\hline & $t_{1}$ & $t_{2}$ & $t_{3}$ & $t_{4}$ & $t_{5}$ & & & & \\
\hline $\mathrm{DE}$ & 0.790 & 0.402 & 0.455 & -0.501 & -1.858 & - & - & - & - \\
\hline CMDE & 0.836 & 0.559 & 0.864 & 0.445 & 0.442 & +2.703 & 369 & 251.43 & 620.43 \\
\hline GMDE & 0.858 & 0.575 & 0.879 & 0.466 & 0.512 & +2.801 & 383 & 263 & 646 \\
\hline LMDE & 0.803 & 0.509 & 0.710 & 0.086 & -0.314 & +1.948 & 266 & 147 & 413 \\
\hline
\end{tabular}




\title{
CONCLUSION
}

In the present study we considered the design optimization of a squirrel-cage three-phase induction motor by employing one basic and three modified DE algorithms, namely CMDE, GMDE, and LMDE. Such type of study is very useful in the present-day scenario when energy conservation is of significant and primary importance. A $7.5 \mathrm{~kW}$ motor has been designed as an illustrative example. Textile spinning load was considered as the input of design optimization for minimum operating cost of the motor. The results obtained by the algorithms were compared with the typical industrial motor. On the basis of the results obtained, the following conclusions may be drawn:

- Out of the four algorithms considered, GMDE and CMDE are apparently more suitable for the design of IMs for industrial applications. LMDE did not perform as well as the other algorithms, and the performance of the basic DE was the worst.

- We observed that the no-load current constraint was more influenced in the optimized design for minimum power consumption or more savings, especially on light loads.

- In terms of energy conservation, we see that the efficiency obtained by $\mathrm{DE}$ in the case of motor designs for general applications is 0.88 whereas, for CMDE and GMDE, the efficiency comes out to be around 0.92.

- As far as the operating cost effectiveness is considered, we can see that $\$ 646$ can be saved in a $7.5 \mathrm{~kW}$ motor per year if it is designed with the consideration of service conditions, i.e., load diagram. This savings will be more in the case of large capacity motors.

- We also see that there is a small increase in the manufacturing cost of the motor, which, however, can be allowed when efficiency or operating cost optimization is performed. This will not create any significant effect on the economics of process industries.

- As far as power quality issues as a result of power electronic controllers and extra investments are considered, we can say that this approach would be an attractive alternative to the work reported in Thanga Raj, Srivastava, and Agarwal (2008b).

\section{NOMENCLATURE}

\author{
$S \quad$ KVA rating of the motor \\ $K_{w} \quad$ winding factor \\ $f \quad$ supply frequency \\ $\phi \quad$ flux \\ $T_{p h} \quad$ stator winding turns per phase
}


$I_{p h} \quad$ rated full-load current per phase

$D$ stator bore diameter

$L \quad$ stack length

$P_{o} \quad$ output power

$p \quad$ number of poles

$d_{s s} \quad$ depth of stator slot

$Y$ pole pitch

$S_{1} \quad$ number of stator slots

$S_{2} \quad$ number of rotor slots

$S_{f} \quad$ stator slot fullness factor

$W_{t} \quad$ weight of the stator teeth

$W_{c} \quad$ weight of the stator core

$W_{r} \quad$ weight of the rotor iron

$\delta_{i} \quad$ stamping material density, $\mathrm{kg} / \mathrm{m}^{3}$

$\delta_{c} \quad$ stator winding material density, $\mathrm{kg} / \mathrm{m}^{3}$

$\delta_{r} \quad$ rotor winding materials density, $\mathrm{kg} / \mathrm{m}^{3}$

$O D$ outside diameter of the stator core

$L_{i} \quad$ net core length

$t_{s} \quad$ mean stator tooth width

$a_{s r}$ area of rotor slot

$W_{s w} \quad$ weight of the stator winding

$W_{r w}$ weight of the rotor winding

$a_{b}$ rotor bar area

$L_{r} \quad$ length of rotor bar

$a_{e} \quad$ end ring cross section

$D_{e} \quad$ end ring diameter

$\rho_{c} \quad$ specific resistivity of stator winding material

$\rho_{r} \quad$ specific resistivity of rotor winding material

\section{REFERENCES}

Anderson, O. W. 1967. Optimum design of electrical machines. IEEE Transactions on Power Apparatus and Systems PAS-86:707-711.

Appelbaum, J., and M. S. Erlicki. 1964. A problem of economic optimization of electric equipment design. IEEE Transactions on Communication and Electronics 88:773.

Appelbaum, J., and M. S. Erlicki. 1965. Optimized parameter analysis of an induction motor. IEEE Transactions on Power Apparatus and Systems 84:1017-1024.

Bharadwaj, D. G. 1979. "Application of Certain Optimization Techniques for Cage Induction Machine." $\mathrm{PhD}$ Thesis, University of Roorkee, India.

Bharadwaj, D. G., K. Venkatesan, and R. B. Saxena. 1979a. Induction motor design optimization using constrained Rosenbrock method (Hill algorithm). Computer and Electrical Engineering 5:41-46.

Bharadwaj, D. G., K. Venkatesan, and R. B. Saxena. 1979b. Optimization techniques applied to induction motor design-A comparative study. Computer and Electrical Engineering 6:117-122.

Bhuvaneswari, R., and S. Subramanian. 2005. Optimization of three-phase induction motor design using simulated annealing algorithm. Electric Power Components and Systems 33:947-956.

Boglietti, A., A. Cavognino, L. Ferraris, M. Lazzari, and G. Luparia. 2005. No tooling cost process for induction motors energy efficiency improvements. IEEE Transactions on Industrial Applications 41 (3): 808-816. 
Brest, J., S. Greiner, B. Boškovic, M. Mernik, and V. Žumer. 2006. Self-adapting control parameters in differential evolution: A comparative study on numerical benchmark problems. IEEE Transactions on Evolutionary Computation 10 (6): 646-657.

Cunkas, M., and R. Akkaya. 2006. Design optimization of induction motor by genetic algorithm and comparison with existing motor. Mathematical and Computational Applications 11 (3): 193-203.

Das, S., A. Abraham, and A. Konar. 2008. Adaptive clustering using improved differential evolution algorithm. IEEE Transactions on Systems, Man and Cybernetics Part A 38 (1): 218-237.

Faiz, J., and M. B. B. Sharifian. 1995. Optimum design of a three phase squirrel-cage induction motor based on efficiency maximization. International Journal of Computers and Electrical Engineering 21 (5): 367-373.

Faiz, J., and M. B. B. Sharifian. 2001. Optimal design of three-phase induction motors and their comparison with a typical industrial motor. Computers and Electrical Engineering 27 (2): 133-144.

Faiz, J., M. Ghaneei, A. Heyhani, and A. B. Proca. 2000. Optimal design of induction motor for electric vehicle. Electric Machines and Power Systems 28:1177-1194.

Fei, R., E. F. Fuchs, and H. Haung. 1989. Comparison of two optimization techniques as applied to three-phase induction motor design. IEEE Transactions on Energy Conversion 4 (4): 651-660.

Fiacco, A. V., and G. P. McCormik. 1964a. The sequential unconstrained minimization technique for nonlinear programming, a primal-dual method. Management Science 10 (2): 360-366.

Fiacco, A. V., and G. P. McCormik. 1964b. Computational algorithm for the sequential unconstrained minimization technique for nonlinear programming. Management Science 10 (4): 601-617.

Goldberg, D. 1986. Genetic algorithms in search optimization and machine learning. Reading, MA: Addison -Wesley.

Han, G. J., and S. S. Shapiro. 1967. Statistical models in engineering. UK: John Wiley and Sons.

Idir, K., L. Chang, and H. Dai. 1997. A new global optimization approach for induction motor design. Proceedings of the IEEE Canadian conference on electrical and computer engineering. 870-873.

Karaboga, D., and S. Okdem. 2004. A simple and global optimization algorithm for engineering problems: Differential evolution algorithm. Turkish Journal of Electrical. Engineering 12 (1): 53-60.

Kim, J.-W., B.-T. Kim, and B. Kwon II. 2005. Optimal stator slot design of inverter-fed induction motor in consideration of harmonic losses. IEEE Transactions on Magnetics 41 (5): 2012-2015.

Kim, M.-K., C.-G. Lee, and H.-K. Jung. 1998. multiobjective optimal design of three-phase induction motor using improved evolution strategy. IEEE Transactions on Magnetics 34 (5): 2980-2983.

Kioskesidis, I., and N. Margaris. 1996. Loss minimization in scalar controlled induction motor drives with search controller. IEEE Transactions on Power Electronics 11 (2): 213-220.

Koechli, C., B. K. Fussell, S. R. Prina, D. A. James, and Y. Periyard. 2004. Design optimization of induction motors for aerospace applications. In Proceedings of the IEEE Industry Applications Conference, 2501-2505. Seattle, WA.

Lampinen, J., and I. Zelinka. 2000. On stagnation of the differential evolution algorithm. In Proceedings of MENDEL 2000, 6th international Mendel conference on soft computing, ed. P. Ošmera, 76-83. Brno, Czech Republic: Technical University Press.

Li, C., and A. Rahman. 1990. Three-phase induction motor design optimization using the modified Hooke-Jeeves method. International Journal of Electrical Machines and Power Systems 18:1-12.

Maljkovic, Z., M. Cettolo, and M. Pavlica. 2001. The Impact of the induction motor on short-circuit current. IEEE Industry Applications Magazine 7 (4): 11-17.

Murthy, S. S., L. Shridhar, B. Singh, C. S. Jha, and B. P. Singh. 1994. Design of energy efficient motor for irrigation pumps operating under realistic conditions. Proceedings of IEE Electrical Power Applications 141 (6): 269-274.

Omran, M., A. P. Engelbrecht, and A. Salman. 2005. Differential evolution methods for unsupervised image classification. In Proceedings of the 7th Congress on Evolutionary Computation 2:966-973.

Omran, M., A. Salman, and A. P. Engelbrecht. 2005. Self-adaptive differential evolution. computational intelligence and security PT 1, Proceedings Lecture Notes In Artificial Intelligence 3801:192-199.

Padma, S., R. Bhuvaneswari, and S. Subramanian. 2007. Application of soft computing techniques to induction motor design. COMPEL: The International Journal for Computation and Mathematics in Electrical and Electronic Engineering 26 (5): 1324-1345.

Palanichamy, C., C. Nadarajan, P. Naveen, N. S. Babu, Dhanalakshmi. 2001. Budjet constrained energy conservation-An experience with a textile industry. IEEE Transactions on Energy Conversion 16 (4): $340-345$. 
Pant, M., R. Thangaraj, and V. P. Singh. 2009. Optimization of mechanical design problems using improved differential evolution algorithm. International Journal of Recent Trends in Engineering 1 (5): 21-25.

Rahnamayan, S., H. R. Tizhoosh, and M. M. A. Salama. 2008. Opposition-based differential evolution. IEEE Transactions on Evolutionary Computation 12 (1): 64-79.

Ramarathnam, R., and B. G. Desai. 1971. Optimization of polyphase induction motor design: A nonlinear programming approach. IEEE Transactions on Power Apparatus and Systems PAS-90 (2): 570-578.

Ramarathnam, R., B. G. Desai, and V. Subba Rao. 1973. A comparative study of minimization techniques for optimization of induction motor design. IEEE Transactions on Power Apparatus and Systems PAS-92 (5): 1448-1454.

Rosenbrock, H. H. 1960. An automatic method of finding the greatest or least value of function. Computer Journal 3:175-184.

Schittkowski, K. 1985. NLPQL: A Fortran subprogram solving constrained nonlinear programming problems. Annals of Operation Research 5:485-500.

Singh, C., and D. Sarkar. 1992. Practical considerations in the optimization of induction motor design. IEE Proceedings-B Electric Power Applications 139 (4): 365-373.

Singh, B., and B. N. Singh. 1993. Experience in the design optimization of a voltage source inverter-fed squirrel cage induction motor. Electric Power Systems Research 26:155-61.

Storn, R., and K. Price. 1995. Differential evolution - A simple and efficient adaptive scheme for global optimization over continuous spaces. Technical Report, International Computer Science Institute, Berkley.

Thanga Raj, C. 2009. “Optimal Design and Control of Three-Phase Induction Motor." PhD Thesis, Indian Institute of Technology Roorkee, India.

Thanga Raj, C., S. P. Srivastava, and P. Agarwal. 2008a. Realization on particle swarm optimized induction motor via SPEED/PC-IMD. IAENG International Journal of Computer Science 16 (4): 486-492.

Thanga Raj, C., S. P. Srivastava, and P. Agarwal. 2008b. Differential evolution based optimal control of induction motor serving to textile industry. IAENG International Journal of Computer Science 35 (2): 201-208.

Thangaraj, R., M. Pant, and A. Abraham. 2010. New mutation schemes for differential evolution algorithm and their application to the optimization of directional overcurrent relay settings. Applied Mathematics and Computation 216 (2): 532-544.

Thangaraj, R., M. Pant, and K. Deep. 2010. Optimal coordination of overcurrent relays using modified differential evolution algorithms. Engineering Applications of Artificial Intelligence 23 (5): 820-829.

Thangaraj, R., M. Pant, A. Abraham, K. Deep, and V. Snasel. 2010. Differential evolution using a localized cauchy mutation operator. In IEEE international conference on systems, man and cybernetics, 3710-3716, Istanbul, Turkey.

Wieczorek, J. P., O. Gol, and Z. Michalewicz. 1998. An evolutionary algorithm for the optimal design of induction motors. IEEE Transactions on Magnetics 34 (6): 3882-3887. 